\title{
INVENTARISASI PARASITOID HAMA PENGGULUNG DAUN PISANG (Erionota thrax L.) DI KOTA METRO DAN SEKITARNYA PROVINSI LAMPUNG
}

\author{
Yudi Des Yulian, Lestari Wibowo \& Indriyati \\ Jurusan Agroteknologi, Fakultas Pertanian Universitas Lampung \\ J1. Prof. Soemantri Brojonegoro, No.1 Bandar Lampung 35145 \\ Email : Yudidesyulian@ymail.com
}

\begin{abstract}
ABSTRAK
Kota Metro merupakan salah satu daerah penghasil pisang di Provinsi Lampung, dan mempunyai potensi yang menjanjikan apabila dikembangkan secara maksimal. Dalam budidaya tanaman pisang banyak faktor yang dapat menjadi kendala, diantaranya adalah serangan hama. Salah satu hama yang sering menyerang tanaman pisang adalah hama penggulung daun pisang (Erionota thrax L). Saat ini pengendalian organisme pengganggu tanaman (opt) yang ramah lingkungan terus dikembangkan, antara lain adalah dengan memanfaatkan musuh alami dalam penerapan pengendalian hayati. Penelitian ini bertujuan untuk menginventarisasi parasitoid hama penggulung daun pisang (E. thrax) serta menghitung persentase parasitasinya di Kota Metro dan sekitarnya, Provinsi Lampung. Pada penelitian ini digunakan metode survei lapang dengan mengambil sampel hama pada 4 kecamatan dengan tiap kecamatan diambil 2 desa pengamatan. Hasil penelitian yang didapat adalah ditemukannya berbagai jenis parasitoid di Kota Metro dan sekitarnya yaitu Brachymeria sp., Xanthopimpla sp. dan Famili Tachinidae. Tingkat parasitasi berbagai jenis parasitoid tertinggi ditemukan di Kecamatan Metro Pusat sebesar $25 \%$.
\end{abstract}

Kata Kunci: Erionota thrax L., inventarisasi, Kota Metro, parasitoid.

\section{PENDAHULUAN}

Pisang merupakan salah satu buah yang sangat digemari oleh sebagian besar masyarakat. Selain merupakan sumber zat pengatur tubuh, buah pisang juga sebagai sumber tenaga atau karbohidrat dan energi. Selain dapat dinikmati sebagai buah segar, pisang juga dapat diolah menjadi berbagai macam produk olahan (Novianti, 2008).

Negara Indonesia adalah salah satu negara penghasil pisang terbesar di Asia. Hal ini dikarenakan 50\% dari produksi pisang Asia berasal dari Indonesia, dan setiap tahun produksinya terus mengalami peningkatan (Satuhu \& Supriyadi, 2007). Menurut Satyantari et al. (1999), hampir semua wilayah di Indonesia cocok untuk perkebunan pisang tetapi untuk pengembangan tanaman pisang secara komersial harus memperhatikan lokasi yang cocok bagi tanaman pisang. Kota Metro merupakan salah satu daerah penghasil pisang di Provinsi Lampung, dan mempunyai potensi yang menjanjikan apabila dikembangkan secara maksimal. Menurut BPS ( 2007 ), pada tahun 2006 produksi buah pisang di kota Metro sebesar 174 ton meliputi pisang ambon, pisang kepok, pisang raja, pisang raja sere dan lain-lain. Salah satu hama yang sering menyerang tanaman pisang adalah hama penggulung daun pisang (Erionota thrax L). E. thrax menyerang bagian daun pisang dan apabila dibiarkan tanaman akan menjadi gundul serta hanya tampak tulang daunnya. Larva dari hama penggulung daun pisang berwarna hijau muda dan ditutupi lapisan tepung berwarna putih dengan panjang sekitar $7 \mathrm{~cm}$. Larva ini begitu keluar dari telur akan memotong lamina daun mulai dari pinggir dan menggulungnya hingga akhirnya daun menjadi kering, sobek-sobek serta mengakibatkan tanaman mati bila dibiarkan terus menerus (Satuhu dan Supriyadi, 2007).

Pengendalian hayati merupakan pengendalian hama dengan memanfaatkan musuh alami yang berada di alam. Salah satu musuh alami yang dapat dimanfaatkan untuk mengendalikan hama adalah parasitoid. Parasitoid merupakan serangga yang hidup menjadi parasit di dalam atau pada tubuh serangga inang, dan membunuhnya secara pelan-pelan (Direktorat Perlindungan Perkebunan, 2002). Adapun tujuan dilakukannya penelitian ini adalah untuk menginventarisasi parasitoid hama penggulung daun pisang (Erionota thrax L.) serta menghitung persentase parasitasinya di Kota Metro dan sekitarnya, Provinsi Lampung.

\section{BAHAN DAN METODE}

Penelitian dilakukan di Kota Metro pada Kecamatan Metro Timur (Desa Tejo Agung dan Tejo 
Sari); Kecamatan Metro Barat (Desa Ganjar Agung dan Ganjar Asri); Kecamatan Metro Utara (Desa Banjar Sari dan Purwo Asri); Kecamatan Metro Pusat (Desa Hadimulyo Barat dan Yosomulyo). Kecamatan Trimurjo yang berada di Kabupaten Lampung Tengah (Desa Tempuran dan Purwodadi). Kabupaten Lampung Timur pada Kecamatan Pekalongan (Desa Adirejo dan Sidodadi); Kecamatan Metro Kibang (Desa Kibang dan Sumber Agung). Penelitian dilaksanakan pada bulan Desember 2014 hingga bulan Maret 2015.

Alat dan bahan yang digunakan adalah gunting, cutter, lem kayu, stoples plastik mikroskop stereo, kuas kecil, kain kasa, label, gelang karet, buku kunci identifikasi Hymenoptera, pinset, cawan petri, botol film nampan, kamera, isolasi, alat tulis, hama penggulung daun pisang dari fase larva dan pupa serta alkohol $70 \%$.

Penelitian dilakukan dengan menggunakan metode survei lapang. Tahap pertama penelitian adalah pengambilan sampel E. thrax, selanjutnya pada tahap kedua adalah mengamati dan mengidentifikasi parasitoid yang didapat di lapangan dari hama penggulung daun pisang. Terakhir pada tahap ketiga adalah pengolahan data yang mencakup penghitungan persentase parasitasi terhadap hama penggulung daun pisang. Metode ini dilakukan dengan mengambil sampel E. thrax pada 4 kecamatan yang ada di Kota Metro yaitu Kecamatan Metro Barat, Metro Timur, Metro Utara, dan Metro Pusat. Di Kabupaten Lampung Tengah mengambil Kecamatan Trimurjo serta di Kabupaten Lampung Timur mengambil Kecamatan Pekalongan dan Metro Kibang. Pada setiap kecamatan terdiri dari 2 desa, dari setiap desa diambil 20 sampel gulungan daun pisang yang terserang hama. Secara keseluruhan total sampel yang terkumpul berjumlah 280 sampel gulungan daun pisang.

Pelaksanaan penelitian adalah pembuatan stoples pemeliharaan dan pengambilan sampel di lapangan. Pada pembuatan stoples pemeliharaan, wadah yang digunakan untuk pemeliharaan sampel gulungan Erionota thrax L. adalah dengan menggunakan gelas plastik minuman yang memiliki ketinggian $22 \mathrm{~cm}$, diameter $8 \mathrm{~cm}$, transparan, serta mudah dibuka dan ditutup saat pengamatan. Pada pengambilan sampel di lapangan, sampel yang diambil merupakan bagian daun pisang yang terserang E. thrax berupa gulungangulungan daun. Proses Pengambilan sampel pada tiap desa dilakukan dengan membuat garis transek sepanjang $\pm 2 \mathrm{~km}$ di areal pertanaman pisang. Sepanjang garis transek ditentukan 5 titik sampel dengan jarak antara titik sampel di areal garis transek adalah $500 \mathrm{~m}$ dengan jumlah 4 sampel gulungan daun pisang per titik.

Sampel yang telah diperoleh selanjutnya dicatat berupa tanggal pengambilan, fase sampel (larva atau pupa ), kondisi sampel (sehat/terparasit), jenis pisang, dan lokasi pengambilan. Setiap sampel gulungan daun pisang yang diperoleh dari lapang ditempatkan di dalam stoples pemeliharaan. Stoples pemeliharaan diletakkan di atas kotak kardus berukuran $30 \mathrm{~cm}$ x $18 \mathrm{~cm}$. Di setiap kotak kardus berisi 10 tabung gelas plastik.

Pengamatan dimulai dari mencatat jenis parasitoid yang muncul dari setiap stadia hama, mencatat tanggal munculnya parasitoid tersebut, dan menghitung jumlah parasitoid yang muncul dari masing-masing jenis parasitoid. Imago dari parasitoid yang telah keluar kemudian dimasukkan ke dalam tabung film yang berisi alkohol 70\% untuk diawetkan sehingga memudahkan proses pengamatan. Setelah itu dilakukan identifikasi parasitoid dengan menggunakan mikroskop stereo dan buku kunci identifikasi Hymenoptera karangan Henri Goulet dan John T. Huber (1993). Untuk selanjutnya dilakukan pengambilan gambar parasitoid dengan kamera.

Setelah dilakukan pengamatan dan identifikasi terhadap parasitoid yang muncul, proses selanjutnya yaitu menghitung Rataan indeks parasitasi terhadap hama penggulung daun pisang. Tujuannya untuk mengetahui kemampuan dari masing-masing parasitoid telur, larva, dan pupa terhadap inang (Hasyim dkk., 2003). Rumus untuk menghitung persentase parasitasi adalah sebagai berikut :

$$
\mathrm{RIP}(\%)=(\mathrm{N} 2 / \mathrm{N} 1) \times 100 \%
$$

Keterangan :

RIP = Rataan Indeks Parasitasi

$\mathrm{N}_{1} \quad$ = Jumlah larva atau pupa yang diambil dan dipelihara di laboratorium

$\mathrm{N}_{2} \quad$ = Jumlah larva atau pupa yang terserang parasitoid

\section{HASIL DAN PEMBAHASAN}

Dari hasil penelitian inventarisasi parasitoid $E$. thrax didapat berbagai jenis parasitoid yang ditemukan di berbagai desa di Kota Metro dan sekitarnya yang tertera dalam Tabel 2. Dari berbagai jenis parasitoid yang ada pada Tabel 1, terlihat bahwa parasitoid Brachymeria sp. mendominasi keberadaan di setiap lokasi pengamatan. Sedangkan parsitoid dari famili Tachinidae hanya ditemukan di 3 lokasi pengamatan yaitu Desa Purwo Asri, Adirejo, dan Sumber Agung. Demikian juga dengan parasitoid Xanthopimpla sp. hanya ditemukan di 3 lokasi pengamatan yaitu desa Tempuran, Hadimulyo Barat, dan Ganjar Agung.

Brachymeria sp. memarasit hama E. Thrax pada fase pupa dengan ciri berupa pupa yang berwarna hitam 
Tabel 1. Jenis-jenis parasitoid E.thrax yang ditemukan di berbagai desa di Kota Metro dan sekitarnya.

\begin{tabular}{cccc}
\hline No & Desa & Kecamatan/Kabupaten & Jenis-jenis Parasitoid \\
\hline 1 & Tempuran & ( Trimurjo, Lamteng) & Brachymeria sp. dan Xanthopimpla sp. \\
2 & Purwodadi & ( Trimurjo, Lamteng) & Brachymeria sp. \\
3 & Yosomulyo & (Metro Pusat, Metro ) & Brachymeria sp. \\
4 & Hadimulyo Barat & (Metro Pusat, Metro ) & Brachymeria sp. dan Xanthopimpla sp. \\
5 & Ganjar Agung & (Metro Barat, Metro ) & Brachymeria sp. dan Xanthopimpla sp. \\
6 & Ganjar Asri & (Metro Barat, Metro) & Brachymeria sp. \\
7 & Purwo Asri & (Metro Utara, Metro ) & Brachymeria sp. dan Famili Tachinidae \\
8 & Banjar Asri & (Metro Utara. Metro ) & Brachymeria sp. \\
9 & Tejo Sari & (Metro Timur, Metro ) & Brachymeria sp. \\
10 & Tejo Agung & (Metro Timur, Metro) & Brachymeria sp. \\
11 & Sidodadi & (Pekalongan, Lamtim) & Brachymeria sp. \\
12 & Adirejo & (Pekalongan, Lamtim) & Brachymeria sp. dan Famili Tachinidae \\
13 & Sumber Agung & (Metro Kibang, Lamtim) & Brachymeria sp. dan Famili Tachinidae \\
14 & Kibang & (Metro Kibang, Lamtim ) & Brachymeria sp. \\
\hline
\end{tabular}

Tabel 2. Rata-rata persentase parasitasi Brachymeria sp. terhadap E. thrax pada beberapa kecamatan di Kota Metro dan sekitarnya.

\begin{tabular}{ccc}
\hline No & Kecamatan & Rata-rata $(\%)$ \\
\hline 1 & Metro Pusat & 22,5 \\
2 & Metro Kibang & 20,0 \\
3 & Metro Timur & 17,5 \\
4 & Trimurjo & 12,5 \\
5 & Metro Barat & 10,0 \\
6 & Pekalongan & 7,5 \\
7 & Metro Utara & 5,0 \\
\hline
\end{tabular}

dan berlubang. Parasitoid ini memiliki panjang tubuh sekitar 5-6 mm dengan warna tubuh hitam mengkilap serta abdomen yang berwarna hitam. Brachymeria sp. memiliki tungkai yang ditumbuhi rambut halus dengan femur tungkai belakang membesar dan bergerigi. Pada bagian ujung femur berwarna kuning (Boucek, 1988 dalam Pamuji et al., 2013). Brachymeria sp. kebanyakan merupakan parasitoid pada pupa dari serangga holometabola, terutama Lepidoptera, tetapi spesies tertentu memarasit Coleoptera, Hymenoptera dan Diptera. Rata-rata persentase parasitasi Brachymeria sp. terhadap E. thrax pada beberapa kecamatan diKota Metro dan sekitarnya dapat dilihat pada Tabel 2. Pada tabel di atas dapat dilihat persentase parasitasi Brachymeria sp terhadap E. thrax tertinggi berada di Kecamatan Metro Pusat dengan tingkat parasitasi sebesar $22,5 \%$.

Pupa E. thrax yang terparasit memiliki ciri berupa warna hitam di hampir keseluruhan bagian pupa.Parasitoid Xanthopimpla sp. memiliki antena sangat panjang, berbentuk filiform dan berwarna coklat kehitaman. Pada bagian toraks terdapat 4 corak hitam. Xanthopimpla sp. memiliki panjang tubuh sekitar 15 mm yang berwarna coklat kekuningan. Parasitoid ini muncul setelah 8 hari menginkubasi pupa E. thrax. Bagian abdomen dari parasitoid ini berwarna kuning kecoklatan serta pada abdomen yang ke arah dorsal terdapat garis hitam tebal di bagian tepi. Panjang sayap depan sekitar $14 \mathrm{~mm}$. Terdapat ovipositor dengan panjang sekitar $6 \mathrm{~mm}$. (Darmawan, 2011 dalam Soviani, 2012).

Rata-rata persentase parasitasi Xanthopimpla sp. terhadap E. thrax pada Kecamatan Metro Barat, Metro Pusat dan Trimurjo dapat dilihat pada Tabel 4. Dari Tabel 3 dapat dilihat bahwa Xanthopimpla sp. ditemukan memarasit $E$. thrax di beberapa lokasi dengan tingkat parasitasi yang berbeda-beda. Persentase parasitasi Xanthopimpla sp. terhadap E. thrax di Kecamatan Metro Barat, Metro Pusat, dan Trimurjo sebesar 2,5\%. Pada sampel E. thrax yang ditambil dari Kecamatan Metro Kibang, Pekalongan , Metro Timur dan Metro Utara tidak ditemukan terparasit oleh Xanthopimpla sp.

Parasitoid jenis ini menyerang E. thrax yang berada pada fase pupa degan ciri pupa berwarna hitam. Ukuran tubuh dari parasitoid ini berkisar 3-15 mm dengan abdomen yang terdapat rambut-rambut kasar berwarna abu-abu/ hitam yang besar dan kuat. Lalat Tachinidae memiliki antena berjumlah 3 ruas dimana ruas ketiga kadang-kadang membulat sering dengan sebuah arista yang tidak berambut dan memanjang (Siwu et al, 2012). Lalat Tachinidae ini relatif mudah dikenali, karena ukuran tubuhnya cukup besar, berambut dan penampilannya seperti lebah atau tabuhan . Pupa $E$. 
Tabel 3. Rata-rata persentase parasitasi Xanthopimpla sp. dan serangan lalat Tachinidae terhadap E. thrax pada Kecamatan Metro Barat, Metro Pusat dan Trimurjo.

\begin{tabular}{cccc}
\hline No & Kecamatan & $\begin{array}{c}\text { Rata-rata persentase } \\
\text { parasitasi Xanthopimpla } \text { sp. }\end{array}$ & $\begin{array}{c}\text { Rata-rata persentase } \\
\text { serangan lalat Tachinidae }\end{array}$ \\
\hline 1 & Metro Barat & 2,5 & 2,5 \\
2 & Metro Pusat & 2,5 & 2,5 \\
3 & Trimurjo & 2,5 & 2,5 \\
\hline
\end{tabular}

Tabel 4. Persentase Parasitasi Berbagai Parasitoid E. thrax di Beberapa Kecamatan di Kota Metro dan Sekitarnya.

\begin{tabular}{ccc}
\hline No & Kecamatan & $\begin{array}{c}\text { Rata-rata } \\
(\%)\end{array}$ \\
\hline 1 & Metro Pusat ( Metro ) & 25,0 \\
2 & Metro Kibang ( Lamtim ) & 22,5 \\
3 & Metro Timur ( Metro ) & 17,5 \\
4 & Trimurjo ( Lamteng ) & 15,0 \\
5 & Metro Barat ( Metro ) & 12,5 \\
6 & Pekalongan ( Lamtim ) & 10,0 \\
7 & Metro Utara ( Metro ) & 7,5 \\
\hline
\end{tabular}

thrax yang diparasit oleh Tachnidae biasanya akan menjadi lebih besar (gemuk) dan berwarna hitam (Novianti, 2008 ). Pupa dari parasitoid lalat Tachinidae memiliki bentuk lonjong dengan guratan spiral berwarna warna hitam. Biasanya pupa yang ada di tiap inang berkisar 1-2 ekor saja. Stadia pupa lalat Tachinidae sekitar 1-2 minggu.

Rata-rata persentase serangan lalat Tachinidae terhadap E. thrax pada Kecamatan Metro Kibang, Pekalongan dan Metro Utara dapat dilihat pada Tabel 4. Dari Tabel 5 dapat dilihat bahwa persentase parasitasi lalat Tachinidae terhadap E. thrax di Kecamatan Metro Kibang, Pekalongan, dan Metro Utara sebesar 2,5\%. Dari data yang tertera pada Tabel 5 dapat dilihat bahwa persentase parasitasi berbagai parasitoid paling besar berada di Kecamatan Metro Pusat ( Metro ) yaitu sebesar $25 \%$. Dengan tingkat persentase parasitasi sebesar $25 \%$, dapat menunjukan bahwa di Kecamatan Metro Pusat mempunyai potensi parasitoid tertinggi dibanding Kecamatan Metro Kibang, Pekalongan, Metro Timur, Metro Utara, Metro Barat, dan Trimurjo.

\section{KESIMPULAN}

Kesimpulan yang diperoleh dari penelitian ini adalah terdapat berbagai jenis parasitoid yang ditemukan di Kecamatan Metro Kibang, Pekalongan, Metro Timur, Metro Utara, Metro Barat, Metro Pusat, dan Trimurjo yaitu Brachymeria sp., Xanthopimpla sp. dan Famili
Tachinidae serta tingkat parasitasi berbagai jenis parasitoid tertinggi ditemukan di Kecamatan Metro Pusat sebesar $25 \%$.

\section{DAFTAR PUSTAKA}

BPS dan Bappeda Provinsi Lampung. 2007. Lampung Dalam Angka 2007. Pemerintah Daerah Provinsi Lampung.

Direktorat Perlindungan Perkebunan dan Direktorat Jenderal Bina Produksi Perkebunan Departemen Pertanian. 2002. Musuh Alami, Hama dan Penyakit Tanaman Lada. Proyek Pengendalian Hama Terpadu Perkebunan Rakyat. Jakarta.

Goulet, H. And J.T. Huber. 1993. Hymenoptera Of The World: An Identification Guide To Families. Research Branch Agriculture. Canada.

Hasyim, A., Kasimar, dan K. Nakamura. 2003. Mortalitas stadia pradewasa hama penggulung daun pisang Erionota thrax (L) yang disebabkan oleh parasitoid. J.Hortikultura. 13(2): 1-7.

Novianti, F. 2008. Hama Penggulung Daun Pisang Erionota Thrax Linnaeus (Lepidoptera: Hesperidae) dan Musuh Alaminya di TempatTempat dengan Ketinggian Berbeda. Skripsi. Institut Pertanian Bogor. Bogor. 43 hal.

Pamuji, R., B. T. Rahardjo, dan H.Tarno. 2013. Kelimpahan dan keanekaragaman hama ulat kantung Metisa plana Walker (Lepidoptera; Psychidae) serta parasitoidnya di Perkebunan Kelapa Sawit Kabupaten Donggala, Sulawesi Tengah. J. HPT . 1 (2): 58-71.

Satuhu, S. dan A. Supriyadi. 2007. Pisang: Budidaya, Pengolahan, dan Prospek Pasar. Penebar Swadaya. Jakarta.

Satyantari, W., U. Sumarwan, dan A. Maulana. 1999. Analisis Produksi dan Konsumsi Pisang Dunia serta peluang ekspor pisang di Indonesia. Agrimedia 5 (2): 57-62. 
Siwu, A.O.S., J. Pelealu, C. L. Salaki, dan Wanta, N. N. 2012. Inventarisasi Parasitoid Hama Tanaman Padi Sawah di Kabupaten Minahasa Utara. Skripsi. Universitas Sam Ratulangi. Minahasa Utara.
Soviani, E. 2012. Identifikasi Parasitoid pada Erinota Thrax dalam Daun Pisang (Musa Paradiciaca). Skripsi. Universitas Pendidikan Indonesia. Bandung. 